\title{
RESEARCH ON OSCILLATIONS OF SELF-DIRECTIONAL WHEELS ON MEANS OF TRANSPORT
}

\author{
Radu Ciuperca, Ana Zaica, Lucretia Popa, Vasilica Stefan \\ National Institute of Research-Development for Machines and Installations \\ Designed to Agriculture and Food Industry, Romania \\ ciupercaradu@yahoo.com,zaica_ana@yahoo.com, lucretia_popa@yahoo.com, \\ valle_vali@yahoo.com
}

\begin{abstract}
The subject of this work is the research carried out on the behavior of theself-directional wheels, part of the running trains which equip the means of transport, their kinematic, as well as the constructive and functional parameters that influence the stability of this type of wheelduring driving. From literature and practice of operation, it is hown that the self-directional wheels, by their constructive and functional nature, show duringdriving two important movements in theform of oscillations, one in the vertical plane and the other in the horizontal plane, movement that manifests itself, when the inherent bumps of the runnway or certain obstacles are passed. The work shows the theoretical aspects of moving the self-directional wheelsto a change, highlighting the mathematical relationships of the two above mentioned oscillations, resulting from the constructive and functional parameters the path influences these oscillations. The experimental research has been carried out with a means of transport produced in bulk, equipped with a two-axle running train of which the rear axles are equipped with self-directional wheels, in combination with a $48 \mathrm{~kW}$ agricultural tractor. To perform the experiments we used the inductive displacement system, MGC plus data acquisition - HBM (HottingerBaldwin-Messtechnik), Catman DAQ data acquisition software, data processing software nCode. The tests were carried out for three values for tire air pressure, five travel speeds and four values for obstacle height. The amplitude of the two types of steering wheel oscillations was recorded in tabular form, the most conclusive expression of their movement and how the oscillations are influenced by the constructive and functional parameters of the means of transport under consideration. The research results have been presented in value terms and show that the vertical oscillation is increased with the speed of travel and the height of the obstacle when passing over uneven surfaces, while, the horizontal oscillation are reduced as travel speeds increase due to increased forces in the telescopic shock absorbers of the axle. Based on the experimental research carried out, the conclusions were formulated to reduce the influence of the oscillations of self-directional wheels on the means of transport stability.
\end{abstract}

Keywords: self-directional wheels, oscillations, stability.

\section{Introduction}

The active safety of motor vehicles includes technologies related to improvements in the basic design of the vehicle, the suspension and wheel guidance system, tire construction, steering system, aerodynamics, running behaviour, maintaining the physical condition and visibility and ability of drivers of motor vehicles to report, methods of establishing measures relevant to the safety of movement and stability [1-4].

The development of means for transporting goods has meant, in addition to their constructive modernization and increasing transport capacity, which leads to the creation of wheel trains capable of supporting these increased capacities, i.e. the transition to wheel trains equipped with two or three axles. The movement of means of transport equipped with three-axis wheel trains results in significantly increased effort and demands, in particular slippages when entering into turns, which can be mitigated by the use of one or two axles fitted with self-directionalwheels.

In addition to the beneficial effects of self-directional wheels, which means an appropriate turn which has implications for reducing tire wear, the track and reducing wear on component parts of the wheel trains, the phenomenon of scaring of wheels, also known as "shimmy", is an disadvantage, which consists of an additional angular oscillation of the self-directional wheels around the vertical axis of the pivot, in addition to the vertical oscillation, when passing over inherent rolling-path irregularities, leading to instability of the means of transport [5-8].

In order to ensure safe driving and to increase stability, the steering system of the self-steering axes shall be as less sensitive as possible to the impact primed on the track side, i.e. a mechanism as rigid as possible, but that does not affect too much shock dampening in the system.

Most of the research carried out and published in the field of the work is mainly linked to the direction of cars, because of the economic importance of this sector of activity and the large number of 
manufacturers. Research has been directed almost exclusively toward technical solutions to improve the safety of the vehicle, in computer-assisted steering systems, with electronic braking control devices, in turns, load transfer on wheels, when travelling on low-adhesion surfaces, automated systems and similar systems $[9 ; 10]$.

The subject of self-directional wheel-rolling systems, which equip large-scale goods transport, has been particularly addressed by manufacturers of such means and less by the scientific and academic world and the results achieved are almost exclusively intellectual protected, that is why references are few and difficult to study. However, the practical achievements in the area of self-steering wheelsystems, which equip high-capacity means of transport, are enough to realize the solutions developed over time to mitigate or eliminate the influences of directional wheel oscillation and safety while driving.

Manufacturers of self-directional rolling systems have found and applied various solutions to mitigate the abovementioned oscillations by choosing appropriate suspensions and runs, on the one hand, and by introducing hydraulic or pneumatic systems to attenuate "shimmy" oscillations, on the other hand. Companies specialized in the manufacture of self-directional rolling stock have adopted technical solutions to mitigate vertical oscillations by using several types of suspension, [11-13], such as:

- suspension with springs in sheets, having the disadvantage of a linear damping characteristic, which reduces the dampening effect when the load increases, but it is the simplest construction and therefore also has low delivery price;

- suspension made of springs in parabolic leaf or pneumatic chamber, which has the advantage of a parabolic damping feature and therefore vertical oscillation damping is more efficient;

- suspension made of springs in parabolic sheets and air chambers have the advantage of achieving constant damping, whatever the load carried or the driving speed.

- In order to mitigate oscillations in a horizontal plane ("shimmy"), manufacturers have over time developed several technical solutions $[11 ; 12]$, such as:

- use of a hydraulic cylinder with a solenoid valve and volumetric compensator fitted on the axle connecting bar, but with the disadvantage that reverse travel is uncontrollable, it has subsequently been improved by using a cylinder that allows the wheels to lock in a position parallel to the track;

- use of pneumatic cameras, which also allow locking in reverse, but which do not provide control over the degree of cushioning;

- the automatic self-steering axle is fitted with two electronically-controlled locking and realignment cylinders. A sensor on the fixed axle detects the direction of the trailer and allows the system to automatically lock one of the two cylinders to ensure smooth operation of the axle. With this configuration, the user does not have to intervene, as the automatic selfsteering axle works autonomously in forward and reverse [13];

- use of two opposing telescopic shock absorbers, which have the advantage that the damping effect increases at high speeds,

- combined solutions with a hydraulic cylinder or telescopic shock absorbers and pneumatic chamber is the optimum solution for removing the "shimmy" phenomenon and allows reverse in optimum conditions, but more complicated constructively and therefore more expensive.

In this work, a theoretical kinematic analysis is carried out of the phenomena occurring on means of transport equipped with self-directional rolling trains, when crossing over uneven road surfaces, identifying the functional parameters and how they influence the running process.

The experimental research was carried out with a bulk-produced means of transport, equipped with a two-axis undercarriage, of which the rear axle is equipped with self-directional wheels. On the basis of the records made, the amplitude of the two types of self-directional wheel oscillations, which most accurately expresses their movement, and the way the oscillations are influenced by the construction and functional parameters of the means of transport under consideration were determined.

On the basis of the experimental research carried out, conclusions and proposals for reducing the influence of the oscillations of the self-directional wheels on the means of transport have been drawn up. 


\section{Materials and methods}

For kinematic analysis of an axis equipped with self-directional wheels, its linear displacement at constant speed above a bump is assumed, in which case two oscillating movements occur, as follows:

- angular oscillation in the vertical direction $\beta$, which causes a vertical movement $X_{V}$ of the wheel-axle beam-steering mechanism assembly, taken from the canter of gravity $C$, Fig. 1 ;

- angular oscillation in the horizontal-transverse direction $\theta$, which causes a transverse movement $X_{H}$ of the self-directional wheel around the vertical axis of the $O$-pivot, Fig. 2.

The two movements may be determined by geometric relationships between the height of the overlap, the characteristics of the tire and the design dimensions of the axle and the corresponding angle speeds, $\omega_{\beta}$ and $\omega_{\theta}$, may be determined by using the linear speeds in the two directions, vertical and horizontal-transverse, respectively $v_{V}$ and $v_{H}$.

The angular speed of the wheel in the vertical plane $\omega_{\beta}$, when passing over an obstacle (leveling), shall be determined according to the vertical component of the ground speed $v_{v}$ and the oscillation radius $r_{a}$, Fig. 1, according to the relationship (1)

$$
\omega_{\beta}=\frac{V_{V}}{r_{a}}
$$

For the determination of $v_{v}$, the wheel-shell impact was considered to be an oblique collision between an elastic body, a wheel and a rigid wall, the obstacle, from the known theory of theoretical mechanics on the oblique stroke [14].

The speeds before and after the impact are broken down into their components, normal (direction of the collision line) and tangential according to the right direction, $\Delta$ tangent to the wheel, Fig. 1, relation (2).

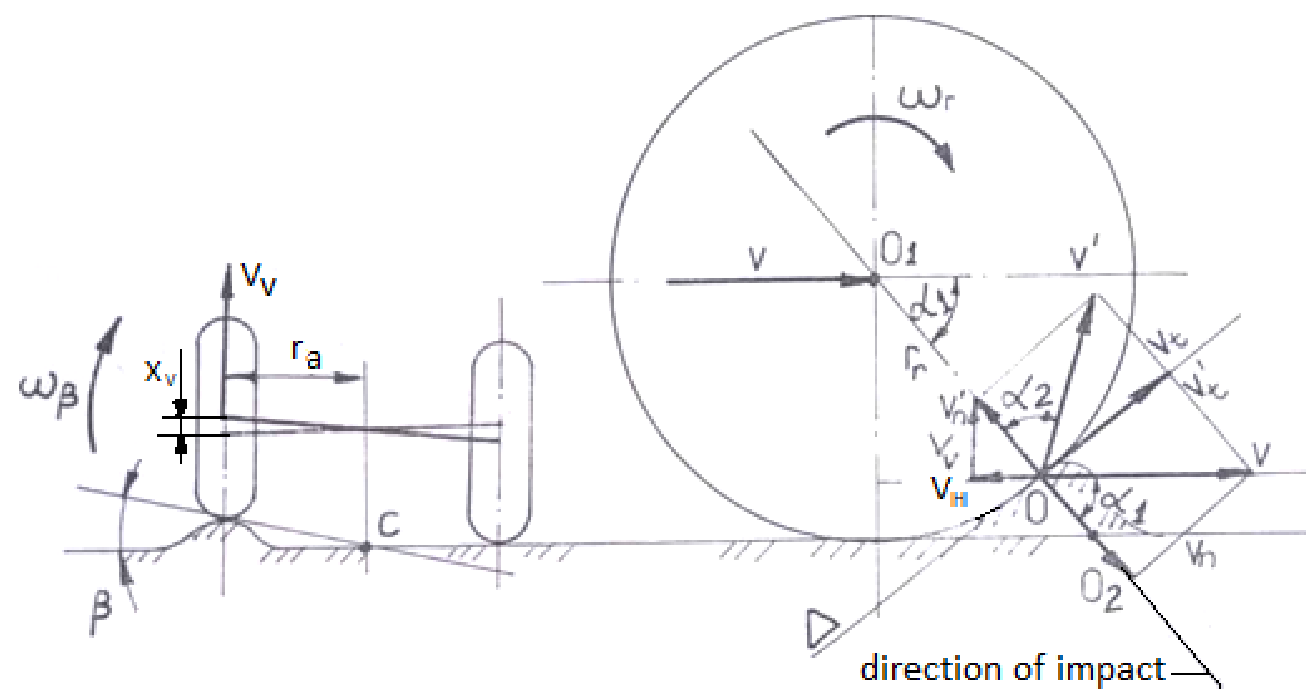

Fig. 1. Wheel oscillation in a vertical plane when colliding with an obstacle

To simplify the relationships, the friction free motion at the moment of the collision was considered, the friction having a low value in the vertical direction and therefore the tangential components of the speeds $v$ and $v$ ' have the same value.

$$
\begin{gathered}
v_{t}^{\prime}=v_{t}, \\
v_{n}^{\prime}=-k \cdot v_{n} .
\end{gathered}
$$

Using Fig. 1, the relationships are written (3).

$$
\begin{gathered}
v_{t}=v \cdot \sin \alpha_{1} ; v_{t}^{\prime}=v^{\prime} \cdot \sin \alpha_{2} \\
v_{n}=v \cdot \cos \alpha_{1}, v_{n}^{\prime}=-v^{\prime} \cdot \cos \alpha_{2}
\end{gathered}
$$

By entering the relationship (3) into (2), the relationship (4) results. 


$$
\begin{gathered}
v^{\prime} \cdot \sin \alpha_{2}=v \cdot \sin \alpha_{1} \\
v^{\prime} \cdot \cos \alpha_{2}=k \cdot v \cdot \cos \alpha_{1}
\end{gathered}
$$

where $k$-refund coefficient of the tire;

$\alpha_{1}-$ angle of incidence (angle between the forward speed and collision line), degrees;

$\alpha_{2}$ - angle of reflection (angle between the speed after impact and impact line), degrees.

By lifting to the square and adding up the equations (4), the impact velocity is given according to the relationship (5).

$$
v^{\prime}=v \sqrt{\sin ^{2} \alpha_{1}+k^{2} \cos ^{2} \alpha_{1}}
$$

The vertical component of the speed after impact will be in accordance with the relationship (5).

$$
v_{V}=v_{n}^{\prime} \cdot s \in \alpha_{1}=k \cdot v_{n} \cdot \sin \alpha_{1}=k \cdot v \cdot \cos \alpha_{1} \cdot \sin \alpha_{1}
$$

The $\alpha_{1}$ angle is determined according to the wheel radius $r_{r}$ and the distance of the obstacle $h$, which are known dimensions according to the relationship (7).

$$
\propto_{1}=\arcsin \frac{r_{r}-h}{r_{r}}=\arcsin \left(1-\frac{h}{r_{r}}\right)
$$

The final relationship for $\omega_{\beta}$ is in accordance with (8).

$$
\omega_{\beta}=\frac{v_{v}}{r_{a}}=\frac{k \cdot v}{r_{a}} \cos \alpha_{1} \cdot \sin \alpha_{1}=\frac{k \cdot v}{2 r_{a}} \sin 2 \alpha_{1}
$$

The refund coefficient of the tire, $k$, is also a known size or can be determined with the relationship (9).

$$
k=\frac{v^{\prime}}{v_{0}}=\frac{\sqrt{2 g h_{1}}}{\sqrt{2 g h_{0}}}=\sqrt{\frac{h_{1}}{h_{0}}}
$$

where $h_{0}$ - height from which the tire is allowed to fall freely on a rigid plane, m;

$h_{1}$ - height at which the tire rises after impact on the rigid plane, $\mathrm{m}$.

The vertical movement of the wheel when passing over an obstacle is determined with the relationship (10).

$$
X_{V}=\beta \cdot r_{a}
$$

in which $r_{a}$ - the axle shaft radius of the undercarriage, $\mathrm{m}$.

The angular speed of the wheel in the horizontal plane, $\omega_{\theta}$, when passing over an obstacle is determined by the horizontal component of the ground speed, $v_{h}$, and by the oscillation radius, $r_{f}$, of the wheel-stub axle assembly, Considered from the centre of rotation of the $\mathrm{O}_{z}$ pivot, Fig. 2, according to the relationship (11).

$$
\omega_{\theta}=\frac{v_{H}}{r_{f}} \cdot \sin \theta
$$

The horizontal component of the speed $v_{H}$, after impact Fig. 2, is determined with the relationship (12).

$$
v_{H}=v_{n}^{\prime} \cdot \cos \alpha_{1} \cdot \sin \theta=k \cdot v \cdot \cos \alpha_{1} \cdot \cos \alpha_{1} \cdot \sin \theta=k \cdot v \cdot \cos ^{2} \alpha_{1} \cdot \sin \theta
$$

and the angular velocity of the wheel in a horizontal plane, $\omega_{\theta}$, is determined with the relationship (13).

$$
\omega_{\theta}=\frac{k \cdot v \cdot \cos ^{2} \alpha_{1}}{r_{f}} \sin \theta
$$


The horizontal movement of the wheel when passing over an obstacle is determined with the relationship (14).

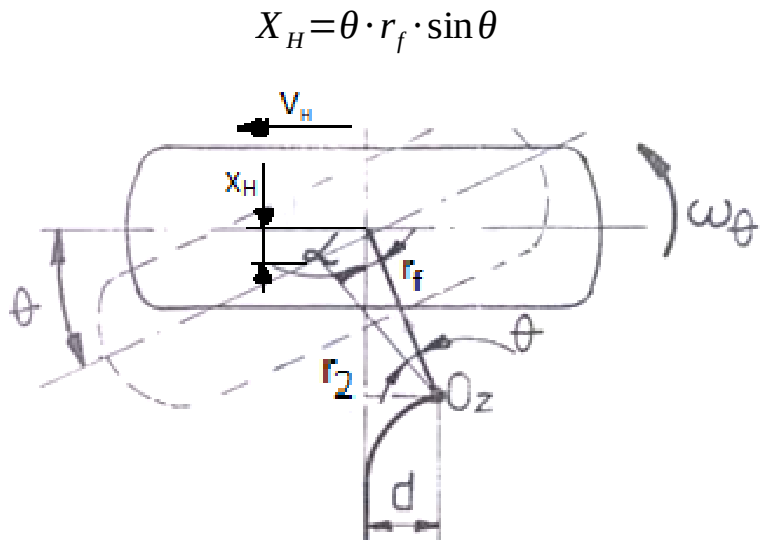

Fig. 2. Wheel oscillation in a horizontal plane when colliding with an obstacle

\section{Resultsand discussion}

The experimental testshasbeencarried out with a means of transport produced in bulk, equippedwith a two-axlerunningtrain of whichtherearaxleisequippedwithself-directionalwheels, in combinationwith a $48 \mathrm{~kW}$ agricultural tractor, Fig. 3.

The attenuation of vertical oscillationsiscarried out bythetyreandpartlybythesuspension of therunningtrain,which, in this case, is made up of twosprings in sheetsandhorizontaloscillations are attenuatedbytwo telescopic dampers, mounted face to face onthemechanism of steeringof theselfdirectionalaxle, Fig.3.

To perform the experiments were used inductive displacement system, MGC plus data acquisition - HBM (Hottinger-Baldwin-Messtechnik), Catman DAQ data acquisition software, data processing software nCode.

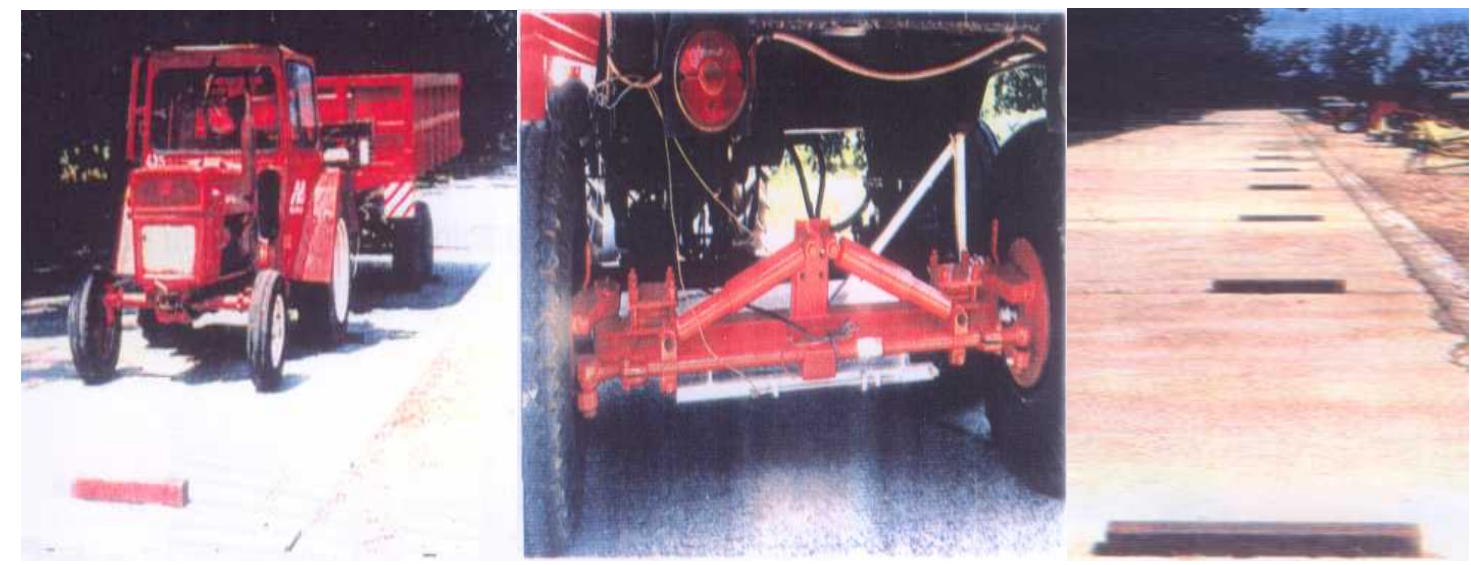

Fig. 3. Trailer agricultural tractor unit during experiments

The experiments were carried out in the following conditions:

- $\quad$ with $m_{r}=1500 \mathrm{~kg}$ per wheel load;

- for5 (five) travel speeds, $v$;

- for 3 (three) tire air pressure values, i.e. $p_{1}=3.5$ bar; $p_{2}=3$ bar; $p_{3}=2.5$ bar;

- for 4 (four) types of obstacles were mounted, two of each type, shaped by square pipes of height $h, 25,50,80,100 \mathrm{~mm}$, spaced $5 \mathrm{~m}$ apart in the direction of travel.

The vertical and horizontal displacement of the self-directional wheel has been determined for all the samples respectively and was measured by two inductive displacement transducers, type W100, W200, which measuring accuracy is $0.01 \mathrm{~mm}$, measured extreme values were eliminated. 
The values are given in Tables 1 to 6 and represent the average of the records for the two obstacles of the same height.

Vertical wheel displacement, $X v$ in $\mathrm{mm}$ for wheel $\operatorname{load} m_{r}=1500 \mathrm{~kg}$ and $p=3.5 \mathrm{bar}$

\begin{tabular}{|c|c|c|c|c|}
\hline \multirow{2}{*}{$\begin{array}{c}\text { Speed } \\
\boldsymbol{v}, \mathbf{m}^{-\mathbf{1}}\end{array}$} & \multicolumn{4}{|c|}{ Height of the obstacle $\boldsymbol{h}, \mathbf{m m}$} \\
\hline$v_{1}=0.62$ & 2.5 & $\mathbf{5 0}$ & $\mathbf{8 0}$ & $\mathbf{1 0 0}$ \\
\hline$v_{2}=1.44$ & 2.7 & 10.00 & 23.33 & 24.58 \\
\hline$v_{3}=1.88$ & 2.2 & 12.22 & 23.33 & 26.66 \\
\hline$v_{4}=2.92$ & 2.0 & 13.52 & 29.62 & 27.40 \\
\hline$v_{5}=4.50$ & 2.0 & 15.83 & 34.07 & 35.00 \\
\hline
\end{tabular}

Vertical wheel displacement, $X v$ in $\mathrm{mm}$ for wheel $\operatorname{load} m_{r}=1500 \mathrm{~kg}$ and $p=3.0 \mathrm{bar}$

\begin{tabular}{|c|c|c|c|c|}
\hline \multirow{2}{*}{$\begin{array}{c}\text { Speed } \\
\boldsymbol{v}, \mathbf{m} \cdot \mathbf{s}^{-1}\end{array}$} & $\mathbf{5}$ Height of the obstacle $\boldsymbol{h}, \mathbf{~ m m}$ \\
\hline$v_{1}=0.70$ & 2.3 & $\mathbf{5 0}$ & $\mathbf{8 0}$ & $\mathbf{1 0 0}$ \\
\hline$v_{2}=1.50$ & 3.0 & 13.33 & 12.22 & 18.51 \\
\hline$v_{3}=1.96$ & 3.0 & 14.25 & 12.22 & 22.22 \\
\hline$v_{4}=2.70$ & 2.5 & 12.22 & 14.44 & 23.4 \\
\hline$v_{5}=4.60$ & 2.0 & 14.07 & 19.16 & 31.66 \\
\hline
\end{tabular}

Table 3

Vertical wheel displacement, $X v$ in $\mathrm{mm}$ for wheel $\operatorname{load} m_{r}=1500 \mathrm{~kg}$ and $p=2.5 \mathrm{bar}$

\begin{tabular}{|c|c|c|c|c|}
\hline \multirow{2}{*}{$\begin{array}{c}\text { Speed } \\
\boldsymbol{v}, \mathbf{m} \cdot \mathbf{s}^{-\mathbf{1}}\end{array}$} & \multicolumn{4}{|c|}{ Height of the obstacle $\boldsymbol{h}, \mathbf{~ m m}$} \\
\hline$v_{1}=0.95$ & 25 & $\mathbf{5 0}$ & $\mathbf{8 0}$ & $\mathbf{1 0 0}$ \\
\hline$v_{2}=1.44$ & 3.5 & 11.48 & 12.59 & 22.59 \\
\hline$v_{3}=2.13$ & 3.0 & 11.11 & 10.37 & 19.25 \\
\hline$v_{4}=2.84$ & 3.3 & 10.00 & 12.22 & 19.25 \\
\hline$v_{5}=4.70$ & 3.0 & 12.00 & 15.92 & 24.3 \\
\hline
\end{tabular}

Table 4

Horizontal wheel displacement, $X_{H}$ in $\mathrm{mm}$ for wheel load $m_{r}=1500 \mathrm{~kg}$ and $p=3.5 \mathrm{bar}$

\begin{tabular}{|c|c|c|c|c|}
\hline \multirow{2}{*}{$\begin{array}{c}\text { Speed } \\
\boldsymbol{v}, \mathbf{m}^{-\mathbf{1}}\end{array}$} & \multicolumn{4}{|c|}{ Height of the obstacle $\boldsymbol{h}, \mathbf{m m}$} \\
\hline & $\mathbf{2 5}$ & $\mathbf{5 0}$ & $\mathbf{8 0}$ & $\mathbf{1 0 0}$ \\
\hline$v_{1}=0.62$ & 3.15 & 8.94 & 23.15 & 33.92 \\
\hline$v_{2}=1.44$ & 6.97 & 7.91 & 26.04 & 26.87 \\
\hline$v_{3}=1.88$ & 3.90 & 7.96 & 12.03 & 16.96 \\
\hline$v_{4}=2.92$ & 5.00 & 7.96 & 10.93 & 12.03 \\
\hline$v_{5}=4.50$ & 1.97 & 7.35 & 10.00 & 11.00 \\
\hline
\end{tabular}

Table 5

Horizontalwheel displacement, $X_{H}[\mathrm{~mm}]$ for wheel load $\mathrm{m}_{\mathrm{r}}=1500 \mathrm{~kg}$ and $\mathrm{p}=3.0 \mathrm{bar}$

\begin{tabular}{|c|c|c|c|c|}
\hline \multirow{2}{*}{$\begin{array}{c}\text { Speed } \\
v, \mathbf{m} \cdot \mathbf{s}^{-1}\end{array}$} & \multicolumn{4}{|c|}{ Height of the obstacle $h, \mathrm{~mm}$} \\
\hline & 25 & 50 & 80 & 100 \\
\hline$v_{1}=0.70$ & 4.07 & 9.55 & 28.28 & 38.42 \\
\hline$v_{2}=1.50$ & 5.00 & 10.00 & 13.15 & 36.00 \\
\hline$v_{3}=1.96$ & 4.90 & 8.25 & 10.90 & 18.00 \\
\hline$v_{4}=2.70$ & 3.95 & 8.50 & 10.50 & 15.65 \\
\hline$v_{5}=4.60$ & 3.95 & 8.95 & 8.65 & 14.00 \\
\hline
\end{tabular}


Horizontalwheel displacement, $X_{H}$ in $\mathrm{mm}$ for wheel load $m_{r}=1500 \mathrm{~kg}$ and $p=2.5 \mathrm{bar}$

Table 6

\begin{tabular}{|c|c|c|c|c|}
\hline \multirow{2}{*}{$\begin{array}{c}\text { Speed } \boldsymbol{v}, \\
\mathbf{m} \cdot \mathbf{s}^{-\mathbf{1}}\end{array}$} & $\mathbf{5}$ Height of the obstacle $\boldsymbol{h , ~ m m}$ \\
\cline { 2 - 5 } & $\mathbf{2 5}$ & $\mathbf{5 0}$ & $\mathbf{8 0}$ & $\mathbf{1 0 0}$ \\
\hline$v_{1}=0.95$ & 6.05 & 10.00 & 30.26 & 37.00 \\
\hline$v_{2}=1.44$ & 6.90 & 10.93 & 18.00 & 16.97 \\
\hline$v_{3}=2.13$ & 6.00 & 9.45 & 15.65 & 14.55 \\
\hline$v_{4}=2.84$ & 5.00 & 10.30 & 11.00 & 13.06 \\
\hline$v_{5}=4.70$ & 5.00 & 9.84 & 9.06 & 13.00 \\
\hline
\end{tabular}

Research results can be reliable data for the manufacturers of power trains, as they present the construction parameters, which influence the movement of the means of transport in order to ensure the safety and security of these means, on the one hand, and for the users of these means, as they have functional parameters, which influence safe movement, on the other hand.

\section{Conclusions}

1. The vertical displacement of the wheel $X v$, thus the oscillation $\beta$, is increased with the speed of travel and the air pressure of the tire when passing over uneven surfaces;

2. Increasing the height of the obstacle leads to a significant increase of displacement with obstacles at lower heights, however, at higher heights;

3. Horizontal displacement of the directional wheels $X_{H}$ are reduced, as the travel speeds increase due to increased forces in the telescopic shock absorbers along with the speed of their pistons, despite the fact that adhesion with soil decreases with increased driving speed;

4. The air pressure in the tire does not have a significant influence on horizontal wheel displacement, with the cross stiffness of the tire varying only slightly with the air pressure in the tire;

5. At the same tire air pressure, as the driving speed increases, there is no significant variation in the wheel motion in a horizontal plane when the height of the obstacle increases.

\section{Acknowledgements}

This work was supported by: Development of the national research-development system, subprogramme 1.2 - Institutional performance - Projects for financing excellence in RDI, contract No. 16PFE.

\section{References}

[1] Câmpian O., Câmpian V., Thierheimer W. Solicitări întransmisiile mecanice ale automobilelor la deplasarea pe drumuri nemodernizate, a XXVIII-a Sesiune de comunicări ştiinţifice cu participare internaţională organizată cu ocazia sărbătoririi a 50 de ani de la înfiinţarea Academiei Tehnice Militare(Requests in the mechanical transmission of cars when traveling on non-dernated roads, the XXVIII Session of international scientific communications held on the occasion of the 50-year anniversary of the establishment of the Military Technical Academy), București, 1999, pp. 27-34,

[2] Câmpian O., Câmpian V., Ciolan GH., Thierheimer W. About the influence of hydrodynamic torque converters on vehicle's dynamic in linear movement, The VIIIth International Conference of Motor Vehicles, Vol. A \& SFRT, Piteşti Romania, 2000, pp. 153-158.

[3] M. C. Clinciu, L. Gaceu, D.C. Thierheimer, W.W. Thierheimer, Some aspects of the active steering for automotive control, Mechanics and Machine Elements, Sofia, Bulgaria,6-8 November 2008, pp. 246-253.

[4] Cojocaru V., Popescu Fl., Thierheimer W.,Cercetări privind îmbunătăţirea ținutei de drum la autoturismele cu tracțiune pe față, Editura TRANSVERSAL(Research on road improvement in front-wheel drive cars, TRANSVERSE publishing house), Târgoviște, Romania, 2014.

[5] Alexandru P., Dudita F, et. al., Mecanismele directiei autovehiculelor (Motor Vehicle Steering Mechanisms ), Editura Tehnica Bucuresti (Technical Publishing House Bucharest), 1977, pp. 177182.

[6] Tecusan N., Ionescu A., Tractoaresi Automobile (Tractors and Automobiles), Editura Didactica si Pedagogica Bucuresti (Technical Publishing House, Bucharest), 1982, pp. 38-52. 
[7] Untaru M, Stoicescu A, Dinamica autovehiculelor pe roti (Dymanics of Wheels Automotive), Editura Didactica si Pedagogica Bucuresti (Technical Publishing House, Bucharest), 1981, pp. 45102.

[8] Dionisia H.J., Sarticiolli F., Eckert J. The Influence of Tire Characteristics on SHIMMY Stability, $23^{\text {rd }} \mathrm{ABCM}$ International Congress of Mechanical Engineering, Rio de Janeiro,Brazil, 2015.

[9] Arun S., Abhishek K., Rejv C., R. C Singh, Study of 4 Wheel Steering System to Reduce Turning Radius and Increase Stability, International Conference of Advance Research and InnovativeICARI, Delhi, India, 2014.

[10] Bae J.J., Kang N. Design Optimization of a Mecanum Wheel to Reduce Vertical Vibrations by the Consideration of Equivalent Stiffness, Publication Shock and Vibration-2016(4):1-8.

[11] ADRAGRI [online][11.02.2020] Available at: www.adraxles.com.

[12] AMB [online][11.02.2020] Available at: www. essieux-bourgogne.net

[13] Colaert Essieux [online][11.02.2020] Available at: www.colaert-essieux.fr.

[14] Atanasiu M, Mecanica (Mechanic), Editura Didactica si Pedagogica Bucuresti (Technical Publishing House, Bucharest), 1973, pp. 383-388. 